\title{
PENGARUH BUDAYA ORGANISASI DAN DISIPLIN KERJA TERHADAP KEPUASAN KERJA PEGAWAI PADA KANTOR CAMAT HU'U KABUPATEN DOMPU
}

\author{
Mirasantika ${ }^{1)}$, Firmansyah Kusumayadi ${ }^{2)}$ \\ Program Studi Manajemen, Sekolah Tinggi Ilmu Ekonomi Bima ${ }^{\mathbf{1 , 2}}$ \\ Mirasantika03.stiebima@gmail.com ${ }^{1)}$, firmansyah90.stiebima@gmail.com ${ }^{2)}$
}

\begin{abstract}
Abstrak
Penelitian ini bertujuan untuk mengetahui pengaruh antara Budaya Organisasi dan Disiplin Kerja terhadap Kepuasan Kerja pegawai pada Kantor Camat Hu.u Kabupaten Dompu. Jenis penelitian yang digunakan dalam penelitian ini adalah Asosiatif. Teknik pengumpulan data dalam penelitian ini mengunakan observasi, wawancara, kuisioner dan studi pustaka. Populasi dalam penelitian ini berjumlah 46 orang responden pegawai pada Kantor Camat Hu.u Kabupaten Dompu. Adapun sampel yang diambil dalam penelitian ini sebanyak 46 orang responden. Tehnik pengambilan sampel menggunakan tekhnik sampel jenuh. Tehnik Analisis data dalam penelitian ini menggunakan regresi linear berganda, uji validitas, uji reliabilitas, koefisien korelasi sederhana, dan uji t dengan bantuan program SPSS 20 for windows. Koefisien menunjukan tingkat keeratan hubungan antara budaya organisasi dan disiplin kerja terhadap kepuasan kerja yaitu dalam hubungan yang kuat. Hal ini dibuktikan dengan tabel pedoman interval koefisien korelasi, koefisien determinasi menunjukan bahwa kepuasan kerja (Y) dipengaruhi oleh budaya organisasi (X1) dan disiplin kerja (X2) yaitu sebesar 49,1\%, sedangkan sisanya sebesar 50,9\% dipengaruhi oleh faktor lain yang tidak termasuk dalam penelitian ini. Hasil dari penelitian ini menunjukkan bahwa Secara parsial Budaya organisasi berpengaruh signifikan terhadap Kepuasan kerja pegawai. Secara parsial Disiplin Kerja tidak berpengaruh signifikan terhadap Kepuasan kerja pegawai. Secara simultan Budaya organisasi dan Disiplin Kerja berpengaruh signifikan terhadap kepuasn kerja pegawai pada Kantor Camat Hu.u Kabupaten Dompu.
\end{abstract}

Kata Kunci : Budaya Organisasi, Disiplin Kerja, Kepuasan Kerja

\section{ABSTRACK :}

This study aims to determine the effect of Organizational Culture and Work Discipline on Employee Job Satisfaction at the District Office of Hu.u, Dompu Regency. This type of research used in this research is associative. Data collection techniques in this study using observation, interviews, questionnaires and literature study. The population in this study amounted to 46 employee respondents at the Hu.u District Office of Dompu Regency. The samples taken in this study were 46 respondents. The sampling technique uses saturated sample techniques. The data analysis technique in this study uses multiple linear regression, validity test, reliability test, simple correlation coefficient, and t test with the help of SPSS 20 for windows program. The coefficient shows the level of closeness of the relationship between organizational culture and work discipline on job satisfaction, namely in a strong relationship. This is evidenced by the correlation coefficient interval guideline table, the coefficient of determination shows that job satisfaction (Y) is influenced by organizational culture (X1) and work discipline (X2) in the amount of 49.1\%, while the remaining $50.9 \%$ is influenced by other factors which is not included in this study. The results of this study indicate that partially organizational culture has a significant effect on employee job satisfaction. Partially Work Discipline has no significant effect on employee job satisfaction. Simultaneously, organizational culture and Work Discipline have a significant effect on employee job satisfaction at the Hu.u District Head Office in Dompu Regency.

Keywords : Organizational Culture, Work Discipline, Job Satisfaction 


\section{PENDAHULUAN}

Dalam upaya mewujudkan aparatur pemerintah yang berkualitas dan berkompeten dalam sebuah organisasi pemerintahan itu sangatlah penting, dimana peranannya sangat diperlukan dalam perencanaan,pelaksanaan, dan pengawasan. Pegawai negeri merupakan ujung tombak pemerintahan dalam usaha memberikan pelayanan terbaik kepada masyarakat. Oleh karena itu, makin berkembang dan diterimanya peranan pemerintahan dalam mencapai tujuannya, maka akan meningkatkan keadilan dan kinerja aparatul sipil negara.

Kantor Camat merupakan organisasi yang menyelenggaraan urusan-urusan pemerintahan umum atas dasar pelimpahan pelaksanaan dari Bupati atau walikota, mengoordinasikan kegiatan pemberdayaan masyarakat, melaksanakan Urusan Pemerintahan yang menjadi kewenangan Daerah kabupaten/kota yang tidak dilaksanakan oleh unit kerja Perangkat Daerah kabupaten/kota yang ada di Kecamatan, membina dan mengawasi penyelenggaraan kegiatan Desa atau kelurahan dan sebagainya.

Dari hasil pengamatan yang peneliti lakukan terlihat bahwa adanya penurunan tingkat kepuasan kerja pegawai disebabkan oleh adanya penerapan budaya organisasi yang masih belum sepenuhnya bisa terlaksana dengan baik.

Budaya Organisasi merupakan norma dan aturan yang menjadi pedoman dan rujukan pegawai dalam bekerja. Menurut Rivai (2011 : 374) budaya organsasi ialah kerangka kerja yang menjadi pedoman tingkah laku sehari-hari dalam membuat keputusan untuk karyawan dan mengarahkan tindakan mereka untuk mencapat tujuan organisasi. Budaya organisasi pada kantor camat $\mathrm{Hu}$ 'u Kabupaten Dompu masih terlihat menurun dimana adanya sikap kesetiaan pegawai terhadap organisasinya yang masih kurang, tanggung jawab dan tingkat partisipasi para pegawai masih kurang terlihat dikarenakan tuntutan pekerjaan dan kebutuhan mereka belum sepenuhnya terpenuhi sehingga berdampak pada menurunnya kepuasan kerja pegawai.

Selain itu sikap ketidakpuasan kerja pegawai dikarenakan menurunnya tingkat disiplin kerja pegawai dimana masih ada beberapa pegawai yang tidak datang kerja, terlambat datang apel pagi dan tidak mengikuti apel sore, sikap menunda pekerjaan serta tidak mengikuti prosedur yang berlaku. Hal itu dikarenakan kurang adanya penerapan koordinasi maupun komunikasi dari pimpinan sehingga berdampak pada menurunnya kepuasan kerja para pegawai pada kantor Camat Hu'u kabupaten Dompu. Disiplin kerja yaitu sikap dan perilaku kerja untuk mentaati segala aturan kerja yang sudah ditetapkan oleh organisasi, kegigihan dalam bekerja, memaksimalkan segala daya upaya guna mencapai hasil yang optimal serta tidak menunda pekerjaan yang diberikan. Menurut Hamali, (2018) mengatakan disiplin adalah sesuatu kekuatan yg berkembang di dalam tubuh karyawan dan menyebabkan karyawan dapat menyesuaikan diri dengan sukarela pada keputusan peraturan, dan nilai nilai tinggi dalam pekerjaan dan perilaku. Mulyadi (2015:48), disiplin adalah rasa sikap hormat atau mental karyawan terhadap peraturan yang dibuat dan diterapkan pada perusahaan.

Berdasarkan permasalahan dan uraian diatas, maka peneliti tertarik untuk melakukan penelitian dengan judul "Pengaruh Budaya Organisai dan Disiplin Kerja Terhadap Kepuasan Kerja Pegawai Pada kantor Camat Hu'u kabupaten Dompu ".

Tujuan dari adanya penelitian ini ingin mengetahui pengaruh Budaya Organisasi yang signifikan secara parsial terhadap Kepuasan Kerja, pengaruh Disiplin Kerja yang signifikan secara parsial terhadap Kepuasan Kerja, pengaruh Budaya Organisasi dan Disiplin Kerja yang signifikan secara simultan terhadap Kepuasan Kerja, serta manakah diantara variabel Budaya Organisasi dan Disiplin 
kerja yang berpengaruh dominan terhadap kepuasan kerja pegawai pada kantor Camat Hu'u Kabupaten Dompu.

\section{METODE PENELITIAN}

Penelitian ini dilakukan pada Kantor Camat Hu'u, Jln. Lintas Lakey Kabupaten Dompu Provinsi Nusa Tenggara Barat. jenis penelitian ini adalah asosiatif. Jenis data yang digunakan adalah data kuantitatif dengan variabel penelitian ada tiga yaitu Budaya Organisasi (X1), Disiplin Kerja (X2) dan Kepuasan Kerja (X3). Sedangkan sumber data menggunakan data primer dan dikumpulkan secara langsung dengan menggunakan kuisioner (angket) dengan memberikan sejumlah daftar pernyataan kepada 46 responden Pegawai pada kantor camat Hu'u Kabupaten Dompu. Adapun tekhnik pengambilan sampel yang digunakan yaitu sampel jenuh. Tehnik Analisis data dalam penelitian ini menggunakan regresi linear berganda, uji validitas, uji reliabilitas, koefisien korelasi sederhana, dan uji $t$ dengan bantuan program SPSS 20 for windows.

\section{HASIL DAN PEMBAHASAN Uji Validitas dan Reabilitas}

Tabel 1 Uji Validitas

\begin{tabular}{|c|c|c|l|l|}
\hline $\begin{array}{c}\text { r. } \\
\text { Hitung } \\
\text { Var. } \\
\text { X1 }\end{array}$ & $\begin{array}{c}\text { r. } \\
\text { Hitung } \\
\text { Var. } \\
\text { X2 }\end{array}$ & $\begin{array}{l}\text { r. } \\
\text { Hitung } \\
\text { Var. Y }\end{array}$ & $\begin{array}{l}\text { r. } \\
\text { Tabel }\end{array}$ & Ket \\
\hline X1.1) & $(\mathrm{X} 2.1)$ & $(\mathrm{Y} .1)$ & 0,300 & Valid \\
0,500 & 0,539 & 0,490 & & \\
\hline (X1.2) & $(\mathrm{X} 2.2)$ & $(\mathrm{Y} .2)$ & 0,300 & Valid \\
0,657 & 0,330 & 0,716 & & \\
\hline$(\mathrm{X} 1.3)$ & $(\mathrm{X} 2.3)$ & $(\mathrm{Y} .3)$ & 0,300 & Valid \\
0,649 & 0,614 & 0,396 & & \\
\hline$(\mathrm{X} 1.4)$ & $(\mathrm{X} 2.4)$ & $(\mathrm{Y} .4)$ & 0,300 & Valid \\
0,566 & 0,468 & 0,682 & & \\
& & & & \\
& & & & \\
& & & & \\
\hline
\end{tabular}

\begin{tabular}{|c|c|c|c|c|}
\hline$(\mathrm{X} 1.5)$ & $(\mathrm{X} 2.5)$ & $(\mathrm{Y} .5)$ & 0,300 & Valid \\
0,603 & 0,599 & 0,731 & & \\
& & & & \\
\hline$(\mathrm{X} 1.6)$ & $(\mathrm{X} 2.6)$ & $(\mathrm{Y} .6)$ & 0,300 & Valid \\
0,799 & 0,573 & 0,724 & & \\
& & & & \\
\hline$(\mathrm{X} 1.7)$ & $(\mathrm{X} 2.7)$ & $(\mathrm{Y} .7)$ & 0,300 & Valid \\
0,685 & 0,441 & 0,730 & & \\
& & & & \\
\hline$(\mathrm{X} 1.8)$ & $(\mathrm{X} 2.8)$ & $(\mathrm{Y} .8)$ & 0,300 & Valid \\
0,576 & 0,372 & 0,792 & & \\
& & & & \\
\hline$(\mathrm{X} 1.9)$ & $(\mathrm{X} 2.9)$ & $(\mathrm{Y} .9)$ & 0,300 & Valid \\
0,742 & 0,595 & 0,664 & & \\
\hline$(\mathrm{X} 1.10)$ & $(\mathrm{X} 2.10)$ & $(\mathrm{Y} .10)$ & 0,300 & Valid \\
0,664 & 0,540 & 0,725 & & \\
& & & & \\
\hline
\end{tabular}

Sumber : Data diolah (2020)

Berdasarkan tabel 1 Hasil pengujian validitas variabel Budaya Organisasi dan Disiplin Kerja terhadap Kepuasan Kerja Pegawai pada Kantor Camat Hu'u Kabupaten Dompu dapat dikatakan valid pada Corrected item-total correlation >0,300. Hasil pengujian validitas ini menunjukkan bahwa pernyataan kuesioner dalam penelitian ini valid.

Tabel 2 Uji Reliabilitas

\begin{tabular}{|c|c|c|}
\hline Variabel & $\begin{array}{c}\text { Cronbach } \\
\text { Alpha }\end{array}$ & Keterangan \\
\hline $\begin{array}{c}\text { Budaya } \\
\text { Organisasi } \\
(\mathrm{X} 1)\end{array}$ & .843 & Reliabel \\
\hline $\begin{array}{c}\text { Disiplin Kerja } \\
(\mathrm{X} 2)\end{array}$ & .862 & Reliabel \\
\hline $\begin{array}{c}\text { Kepuasan } \\
\text { Kerja (Y) }\end{array}$ & .855 & Reliabel \\
\hline
\end{tabular}

\section{Sumber : Data diolah (2020)}

Berdasarkan tabel 2 Hasil pengujian penelitian menggunakan pengukuran ini dapat dikatakan reliabel pada Cronbach alpha $>0,600$. Hasil pengujian reliabilitas ini menunjukkan bahwa pernyataan kuesioner dalam penelitian ini reliabel. 
Uji Asumsi Klasik

1. Hasil Uji Normalitas

\begin{tabular}{|ll|l|}
\hline \multicolumn{2}{|c|}{ One-Sample Kolmogorov-Smirnov Test } \\
\hline $\mathrm{N}$ & $\begin{array}{l}\text { Unstandardiz } \\
\text { ed Residual }\end{array}$ \\
\hline Normal & Mean & 46 \\
Parameters ${ }^{\text {a,b }}$ & Std. & .0000000 \\
& Deviation & 4.35957940 \\
Most Extreme & Absolute & .168 \\
Differences & Positive & .168 \\
& Negative & -.114 \\
Kolmogorov-Smirnov Z & 1.136 \\
Asymp. Sig. (2-tailed) & .151 \\
\hline
\end{tabular}

a. Test distribution is Normal.

b. Calculated from data.
Berdasarkan dari hasil uji normalitas menggunakan metode kolmogorovsmirnov di dapatkan hasil signifikan dari uji normalitas 0,151 dimana hasil tersebut lebih besar dari taraf signifikansi 0,05 sehingga dapat di simpulkan bahwa uji test normalitas dalam penelitian ini adalah berdistribusi normal.

\section{Hasil Uji Multikoliniaritas}

Coefficients $^{\mathrm{a}}$

\begin{tabular}{|c|c|c|c|c|c|c|c|c|}
\hline \multirow{2}{*}{\multicolumn{2}{|c|}{ Model }} & \multicolumn{2}{|c|}{$\begin{array}{l}\text { Unstandardized } \\
\text { Coefficients }\end{array}$} & $\begin{array}{l}\text { Standardized } \\
\text { Coefficients }\end{array}$ & \multirow[t]{2}{*}{$t$} & \multirow[t]{2}{*}{ Sig. } & \multicolumn{2}{|c|}{$\begin{array}{l}\text { Collinearity } \\
\text { Statistics }\end{array}$} \\
\hline & & $\mathrm{B}$ & Std. Error & Beta & & & $\begin{array}{l}\text { Toleranc } \\
\mathrm{e}\end{array}$ & VIF \\
\hline \multirow{3}{*}{1} & (Constant) & 8.410 & 5.044 & & 1.667 & .103 & & \\
\hline & $\begin{array}{l}\text { budaya } \\
\text { organisasi }\end{array}$ & .596 & .166 & .549 & 3.582 & .001 & .504 & 1.986 \\
\hline & disiplin kerja & .220 & .173 & .196 & 1.277 & .209 & .504 & 1.986 \\
\hline
\end{tabular}

a. Dependent Variable: kepuasan kerja

Dari hasil pengujian dengan metode VIF terllihat bahwa nilai tolerance $>0.100$ dan nilai VIF < 10.00 maka dapat disimpulkan bahwa tidak terjadi multikollinieritas.

\section{Hasil Uji Heterokedastisitas}

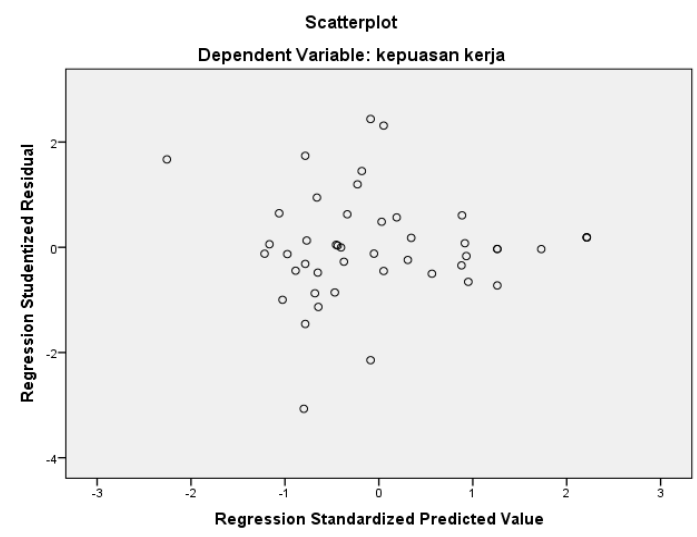

Bentuk gambar diatas, dapat dilihat bahwa penyebaran residual adalah tidak teratur dan tidak membentuk pola. Hal tersebut dapat dilihat pada titik-titik atau plot yang menyebar. Kesimpulan yang dapat diambil adalah bahwa tidak terjadi residual.

\section{Hasil Uji Heterokedastisitas}

Model Summary ${ }^{b}$

\begin{tabular}{|l|l|l|l|l|l|}
\hline Model & $\mathrm{R}$ & $\begin{array}{l}\mathrm{R} \\
\text { Square }\end{array}$ & $\begin{array}{l}\text { Adjusted } \\
\text { R Square }\end{array}$ & $\begin{array}{l}\text { Std. } \\
\text { Error of } \\
\text { the } \\
\text { Estimate }\end{array}$ & $\begin{array}{l}\text { Durbi } \\
\mathrm{n}- \\
\text { Watso } \\
\mathrm{n}\end{array}$ \\
\hline 1 & $.701^{\mathrm{a}}$ & .491 & .468 & 4.460 & 1.601 \\
\hline
\end{tabular}

a. Predictors: (Constant), disiplin kerja, budaya organisasi

b. Dependent Variable: kepuasan kerja 
Nilai di dicari pada distribusi nilai tabel durbin-watson berdasarkan $\mathrm{K}(2)$ dan $\mathrm{n}(46)$ dengan signifikasi 5\%. Nilai Durbin_Watson (d) sebesar 1,601 < batas atas (du) yakni 1,617 dan < (4-du) 4 -
$1,617=2,383$, sebagaimana dasar keputusan dalam uji Durbin-Watson di atas, maka dapat ditarik kesimpulan bahwa tidak terdapat masalah atau gejala autokorelasi.

\section{Analisis Regresi Linear Berganda}

\section{Coefficients $^{\mathrm{a}}$}

\begin{tabular}{|c|c|c|c|c|c|c|c|}
\hline \multirow[t]{2}{*}{ Model } & \multicolumn{2}{|c|}{$\begin{array}{l}\text { Unstandardized } \\
\text { Coefficients }\end{array}$} & \multirow{2}{*}{$\begin{array}{l}\text { Standardized } \\
\text { Coefficients } \\
\text { Beta }\end{array}$} & \multirow[t]{2}{*}{$\mathrm{t}$} & \multirow[t]{2}{*}{ Sig. } & \multicolumn{2}{|c|}{$\begin{array}{l}\text { Collinearity } \\
\text { Statistics }\end{array}$} \\
\hline & $B$ & Std. Error & & & & $\begin{array}{l}\text { Toleranc } \\
\mathrm{e}\end{array}$ & VIF \\
\hline $\begin{array}{l}\text { (Constant) } \\
\text { budaya } \\
\text { organisasi } \\
\text { disiplin kerja }\end{array}$ & $\begin{array}{l}8.410 \\
.596 \\
.220\end{array}$ & $\begin{array}{l}5.044 \\
.166 \\
.173\end{array}$ & $\begin{array}{l}.549 \\
.196\end{array}$ & $\begin{array}{l}1.667 \\
3.582 \\
1.277\end{array}$ & $\begin{array}{l}.103 \\
.001 \\
.209\end{array}$ & $\begin{array}{l}.504 \\
.504\end{array}$ & $\begin{array}{l}1.986 \\
1.986\end{array}$ \\
\hline
\end{tabular}

a. Dependent Variable: kepuasan kerja

a. Nilai konstanta bernilai positif sebesar 8,410 hal ini menunjukkan apabila variabel budaya organisasi dan disiplin kerja bernilai nol, maka kepuasan kerja sebesar 8,410 .

b. Koefisien regresi variabel diskon $\mathrm{X}_{1}$ bernilai positif sebesar 0,596 hal ini menunjukkan bahwa apabila budaya organisasi semakin baik dengan asumsi variabel lain konstan, maka hal tersebut dapat meningkatkan kepuasan kerja sebesar 0,596.

c. Koefisien regresi variabel disiplin kerja $\mathrm{X}_{2}$ bernilai positif sebesar 0,220 hal ini menunjukkan apabila variabel kepercayaan konsumen semakin baik dengan asumsi variabel lain konstan, maka hal tersebut dapat meningkatkan kepuasan kerja sebesar 0,220 .

\section{Analisis koefesien determinasi}

Model Summary ${ }^{b}$

\begin{tabular}{|l|l|l|l|l|l|}
\hline $\begin{array}{l}\text { Mo } \\
\text { del }\end{array}$ & R & $\begin{array}{l}\text { R } \\
\text { Square }\end{array}$ & $\begin{array}{l}\text { Adjusted } \\
\text { R Square }\end{array}$ & $\begin{array}{l}\text { Std. Error } \\
\text { of the } \\
\text { Estimate }\end{array}$ & $\begin{array}{l}\text { Durbin } \\
\text { Watson }\end{array}$ \\
\hline 1 & $.701^{\mathrm{a}}$ & .491 & .468 & 4.460 & 1.601 \\
\hline
\end{tabular}

a. Predictors: (Constant), disiplin kerja, budaya organisasi

b. Dependent Variable: kepuasan kerja
Dari data diatas, dapat diketahui bahwa koefisien determinasi ( $\mathrm{R}$ Square) yang diperoleh sebesar 0,491. Hal ini menunjukkan bahwa variabel budaya organisasi dan disiplin kerja hanya mempengaruhi sebesar $49,1 \%$ terhadap kepuasan kerja. Sedangkan sisanya 50,9\% dipengaruhi oleh variabel lain yang tidak diteliti dalam penelitian ini.

\section{Analisis koefesien korelasi}

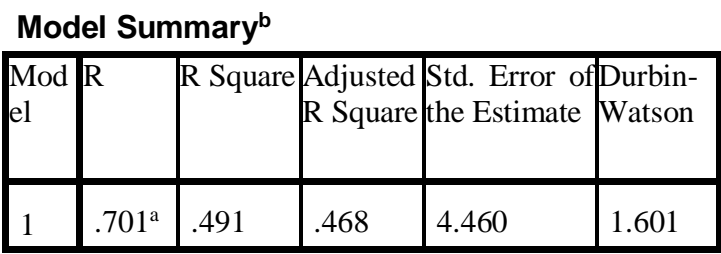

a. Predictors: (Constant), disiplin kerja, budaya organisasi

b. Dependent Variable: kepuasan kerja

Berdasarkan nilai korelasi sebesar 0,701 hal ini menunjukan hubungan antara variable budaya organisasi $\left(\mathrm{X}_{1}\right)$ dan disiplin kerja $\left(\mathrm{X}_{2}\right)$ dengan variabel kepuasan kerja (Y) dengan tingkat hubungan kuat sesuai dengan tabel pedoman interval koefisien korelasi (sugiyono ; 2011). 


\section{Uji simultan (uji F)}

\begin{tabular}{|c|c|c|c|c|c|c|}
\hline Model & & Sum of Squares & df & Mean Square & $\mathrm{F}$ & Sig. \\
\hline \multirow{3}{*}{1} & Regression & 825.603 & 2 & 412.801 & 20.754 & $.000^{\mathrm{b}}$ \\
\hline & Residual & 855.267 & 43 & 19.890 & & \\
\hline & Total & 1680.870 & 45 & & & \\
\hline
\end{tabular}

a. Dependent Variable: kepuasan kerja

b. Predictors: (Constant), Budaya Organisasi, Disiplin Kerja

Dari uji ANOVA atau $F$ test diperoleh $\mathrm{F}$ hitung sebesar 20,754. Untuk menentukan $\mathrm{F}_{\text {tabel }}$ digunakan lampiran statistika $F_{\text {tabel }}$ dengan menggunakan $\alpha=$ $5 \%$. Nilai df1 (jumlah variabel -1 ) atau $3-1=2$ dan df2 (n-k-1) atau $46-2-1$ = 43. Maka diperoleh $\mathrm{F}_{\text {tabel }}$ sebesar 3,21. Hal ini mengartikan bahwasanya nilai

\section{Uji parsial (uji t)}

\section{Coefficients $^{\mathrm{a}}$}

\begin{tabular}{|c|c|c|c|c|c|c|c|c|}
\hline \multirow{2}{*}{\multicolumn{2}{|c|}{ Model }} & \multicolumn{2}{|c|}{ Unstandardized Coefficients } & \multirow{2}{*}{$\begin{array}{l}\text { Standardized } \\
\text { Coefficients } \\
\text { Beta }\end{array}$} & \multirow[t]{2}{*}{$\mathrm{t}$} & \multirow[t]{2}{*}{ Sig. } & \multicolumn{2}{|c|}{ Collinearity Statistics } \\
\hline & & $B$ & Std. Error & & & & Tolerance & VIF \\
\hline \multirow{3}{*}{1} & (Constant) & 8.410 & 5.044 & & 1.667 & .103 & & \\
\hline & $\begin{array}{l}\text { budaya } \\
\text { organisasi }\end{array}$ & .596 & .166 & .549 & 3.582 & .001 & .504 & 1.986 \\
\hline & disiplin kerja & .220 & .173 & .196 & 1.277 & .209 & .504 & 1.986 \\
\hline
\end{tabular}

a. Dependent Variable: kepuasan kerja

Dari data di atas di peroleh $\mathrm{t}_{\text {hitung }}$ untuk (X1) sebesar 3,582, dan 1,277 untuk (X2). Untuk menentukan tabel dapat dilihat dalam lampiran statistika $t_{\text {tabel }}$, dengan menggunakan $\alpha=5 \%: 2=2,5 \%$ (uji 2 sisi) dengan (df) n-k-1 atau 46-2-1 = 43 . Maka diperoleh $t_{\text {tabel }}$ sebesar 2.016. untuk lebih jelasnya dapat dilihat dalam uraian dibawah ini :

a. Variabel Budaya Organisasi memiliki nilai thitung 3,582> tabel 2.016, yang artinya bahwa $\mathrm{H}_{0}$ ditolak dan $\mathrm{H}_{\mathrm{a}}$ diterima, dimana hipotesis $\mathrm{H}_{\mathrm{a}}$ yang menyatakan variabel "Budaya organisasi berpengaruh terhadap Kepuasan kerja" dapat di terima.
$\mathrm{F}_{\text {hitung }}>\mathrm{F}_{\text {tabel }}$ yaitu 20,754 $>3,21$ sehingga $\mathrm{H}_{0}$ ditolak dan $\mathrm{H}_{\mathrm{a}}$ diterima. Yang berarti variabel budaya organisasi dan disiplin kerja secara bersama-sama berpengaruh terhadap kepuasan kerja pada kantor Camat Hu'u Kabupaten Dompu, dapat diterima. 
kepuasan kerja pegawai pada kantor Camat Hu'u Kabupaten Dompu.

2. Disiplin Kerja tidak berpengaruh signifikan terhadap kepuasan Kerja Pegawai Pada kantor Camat Hu'u Kabupaten Dompu.

3. Budaya organisasi dan disiplin kerja secara bersama-sama memiliki pengaruh signifikan terhadap kepuasan kerja pegawai. Hal ini menunjukkan bahwa kedua faktor tersebut memiliki dampak pada peningkatan kepuasan kerja pegawai pada kantor Camat Hu'u Kabupaten Dompu.

Berdasarkan kesimpulan diatas, adapun yang dapat disarankan sebagai berikut:

1. Pimpinan pada kantor Camat Hu'u Kabupaten Dompu perlu memperhatikan dan menciptakan sikap kepuasan kerja pada pegawainya dengan memperhatikan penerapan budaya organisasi yang baik, pemberian contoh disiplin kerja yang baik dan factor lain yang dapat mempengaruhi sikap kepuasan kerja pegawai dalam bekerja sehingga dapat mencapai tujuan organisasi.

2. Diharapkan pada peneliti selanjutnya agar dapat mengembangkan dan memperluas kajian penelitian ini, dengan menambah beberapa variabel independen lain yang belum terdapat dalam penelitian ini misalnya variabel kepemimpinan, motivasi kerja, kompensasi, iklim kerja dan sebagainya.

\section{UCAPAN TERIMA KASIH}

Terima kasih peneliti ucapkan terhadap semua pihak terutama orang tua yang selalu sabar dalam mendidik dan menyemangatiku. Dosen pembimbingku yang selalu mengarahkan dan memberikan masukan perbaikan dalam penyusunan penelitian ini. Terima kasih kepada sahabat yang telah membantu dan berpartisipasi dalam penyusunan penelitian ini.

\section{DAFTAR PUSTAKA}

[1] Ghozali,I. 2013. Aplikasi Analisis Multivariate dengan Program IBM SPSS 21 Update PLS Regresi. Semarang: Badan Penerbit Universitas Diponegoro. Diakses pada 19 januari 2020

[2] Hamali, A. Y. (2018). Pemahaman Manajemen Sumber Daya Manusia. Jakarta: PT. Buku seru.

[3] Mulyadi, D. 2015. Perilaku Organisasi dan Kepemimpinan Pelayanan. Bandung: Alfbeta

[4] Rivai,veithzal.2011, Manajemen Sumber Daya Manusia Untuk Perusahaan:dari teori ke praktik. Jakarta: Raja Grafindo pesada.

[5] Sugiyono. ( 2017 ). Metode Penelitian Kuantitatif, kualitatif, dan $R \& D$. Bandung : Alfabeta. 
Mirasantika, dan Firmansyah K, Pengaruh Budaya Organisasi dan Disiplin Kerja... 